\title{
Zayıf Kaya Kütlelerinde Açılan Modifiye At Nalı Kesitli Tünellerdeki Deformasyon Dağııımının Sayısal Modelleme ile Belirlenmesi
}

\author{
Alaattin SAKCALI ${ }^{1}$ \\ ${ }^{1}$ Atatürk Üniversitesi, Mühendislik Fakültesi, Inşaat Mühendisliği Bölümü, Erzurum.
}

Sorumlu yazar e-posta: alaattinsakcali@atauni.edu.tr, ORCID ID: https://orcid.org/0000-0001-9246-917X

Geliş Tarihi: 10.05.2021 Kabul Tarihi: 14.08.2021

\begin{abstract}
Öz
Tünel kazısı sonrası tünel çevresindeki kaya kütlesinde meydana gelen deformasyonları karakterize etmek tahkimat tasarımı için bir yardımcı araç olarak kullanılabilmektedir. Tünel kazısı sonrası tünel aynasına dik doğrultuda aynanın ön ve arkasındaki deformasyonlar uzunlamasına deformasyon profili (Longitudinal Deformation Profile (LDP)) ile belirlenebilir. Literatürde farklı parametrelerin etkileri de göz önünde bulundurularak LDP’nin oluşturulmasına yönelik eşitlik önerileri vardır. Bu eşitlikler hidrostatik koşullarda tünel kazısı gerçekleştirildiği varsayımı yapılarak dairesel kesitli tüneller için önerilmiştir. Türkiye'de karayolu tünelleri genellikle modifiye at nalı kesitli açılmakta olup tünel aynası çevresindeki deformasyonların tam olarak tahmin edilmesinde zorluklarla karşılaşıımaktadır. Tünel çevresindeki kaya kütlesindeki deformasyonları sayısal modelleme ile analiz etmek mümkündür. Bu çalışmada, Türkiye'de kara yolu tünel kazılarında en çok tercih edilen 2 farklı boyuttaki modifiye at nalı kesitli tünel ele alınmıştır. Belirlenen kesitlerde zayıf kaya kütlesinde açılacak tünel kazısı sonlu farklar yöntemine dayalı FLAC3D ile modellenmiştir. Hidrostatik koşullarda açılan tünelin yanı sıra hidrostatik olmayan koşullar da değerlendirilmiştir. Yatay gerilme / dikey gerilme oranı (k-değeri) 0,5 ile 2 arasında değişen koşullar için belirlenen kesitlerde tüneller tahkimatsız olarak modellenmiştir. Modelden elde edilen deformasyon dağılımlarına ve tavandan tabana doğru $15^{\circ}$ lik açısal değişimle belirlenen yerlerde kaydedilen deformasyon değerleri incelenmiştir. Bu çalışma ile, dairesel olmayan (modifiye at nalı kesitli) tünel kazılarında LDP'nin belirlenmesinde sayısal modellemenin iyi bir yardımcı araç olabileceği sonucu elde edilmiştir.
\end{abstract}

Anahtar kelimeler

Deformasyon dağılımı;

Modifiye at nalı kesit;

Sayısal modelleme;

Tünel

\section{Determination of Deformation Distribution around Modified Horseshoe Cross-sectional Tunnels in Weak Rock Mass}

\begin{abstract}
Characterization of deformations occurring in the rock mass around the tunnel after tunnel excavation can be used as an auxiliary tool for support design. After the tunnel excavation, the deformations in front and behind of the tunnel face in perpendicular direction can be determined with the longitudinal deformation profile (LDP). There are equality proposals by considering the effects of different parameters for the establishment of the LDP in the literature. These equations are proposed for circular section tunnels by assuming that tunnel excavation is carried out under hydrostatic conditions. The highway tunnels in Turkey are generally opened with modified horseshoe cross-section and difficulties are encountered in precisely predicting deformations around the tunnel face. It is possible to analyze the deformations in the rock mass around the tunnel by numerical modeling. In this study, the most preferred modified horseshoe cross-sectional tunnels of 2 different sizes in highway tunnel excavation in Turkey are discussed. The tunnel excavations to be opened in the weak rock mass in the determined sections were modeled with FLAC3D based on finite difference method. In addition to the tunnel opened under hydrostatic conditions, non-hydrostatic conditions were also evaluated. The tunnels in the determined sections for conditions with horizontal stress / vertical stress ratio ( $\mathrm{k}$-value) between 0.5 and 2 were modeled as unsupported. The deformation distributions obtained from the model and the deformation values recorded in the points determined with an angular change of $15^{\circ}$ from the roof to the base were examined. With this study, it is concluded that numerical modeling can be a good auxiliary tool in determining LDP in tunnel excavations with non-circular (modified horseshoe crosssection).
\end{abstract}




\section{Giriş}

Tünel kazısı sonrası tünel çevresindeki kaya kütlesinde oluşacak gerilme ve deformasyonları karakterize etmek tahkimat tasarımı için bir yardımcı araç olarak kullanılabilmektedir. Tünel aynası çevresindeki kaya kütlesinde meydana gelecek gerilme ile deformasyon ilişkisi zemin tepki eğrisi (Ground Reaction Curve (GRC)) ile analiz edilebilirken kullanılacak tahkimat sistemi ise tahkimat karakteristik eğrisi (Support Characteristic Curve (SCC)) ile belirlenebilmektedir. Zemin tepki (GRC) ve tahkimat karakteristik (SCC) eğrileri kullanılarak tahkimat sisteminin davranışı analitik olarak analiz edilebilmektedir. Kapanma-yakınsama (Convergence-Confinement) yönteminde tünel aynasına dik doğrultuda tünel çevresindeki kaya kütlesinde meydana gelecek deformasyonlar ise uzunlamasına deformasyon profili (Longitudinal Deformation Profile (LDP)) ile belirlenebilir.

LDP tünel aynasının önünde ve gerisinde tünel çepherinde meydana gelecek deformasyonların karakterize etmek için yaygın olarak kullanılmakta olup, literatürde LDP'nin belirlenmesine yönelik önerilmiş eşitlikler vardır. Panet ve Guenot (1982) ve Panet (1995) tarafından tünel aynası arkasına $(\mathrm{L} / \mathrm{R} \geq 0)$ doğru meydana gelecek deformasyonların belirlenmesi için Eşitlik 1 önerilmiştir. Corbetta vd. (1991) ise yaptıkları sayısal modelleme çalışmaları sonucunda tünel aynası arkasında ( $\mathrm{L} / \mathrm{R} \geq 0)$ meydana gelecek deformasyonların Eşitlik 2 ile belirlenebileceğini belirmişlerdir. Carranza-Torres ve Fairhurst (2000) çalışmasında, Hoek (1999) tarafından önerilen Eşitlik 3'ü kullanmıştır. Hoek (1999) bu eşitlik önerisini Chern vd. (1998)'nin çalışmasındaki verilere dayanarak yapmıştır.

$\frac{u_{r}}{u_{r}^{M}}=0,25+0,75\left[1-\left(\frac{0,75}{0,75+L / R}\right)^{2}\right]$

$\frac{u_{r}}{u_{r}^{M}}=0,25+0,71\left[1-e^{\left(-1,5(L / R)^{0,7}\right)}\right]$

$\frac{u_{r}}{u_{r}^{M}}=\left[1+e^{\left(\frac{-L / R}{1,1}\right)}\right]^{-1,7}$

Eşitliklerde $u_{r}$ radyal deformasyon, $u_{r}^{M}$ en büyük radyal deformasyon, $\mathrm{L}$ tünel aynasına dikey yöndeki uzaklık, $\mathrm{R}$ ise tünel kazı yarıçapıdır. Bazı araştırmacılar LDP'nin sadece tünel aynasına olan mesafe (L) ve tünel kazı yarıçapı (R)'nin bir fonksiyonu olmadığını bunun yanı sıra farklı parametrelerin de etkili olduğunu belirtmişlerdir. Unlu ve Gercek (2003) Poisson's oranının (७) deformasyon üzerindeki etkisini araştırmış ve aynaya olan mesafe ile kazı yarıçapının yanı sıra Poisson's oranın da deformasyona etki edeceğini vurgulamışlardır. Tünel aynası önünde $(\mathrm{L} / \mathrm{R} \leq 0)$ ve arkasındaki $(\mathrm{L} / \mathrm{R} \geq 0)$ deformasyonların belirlenmesi için sırasıyla Eşitlik 4 ve 5'i önermişlerdir.

$$
\begin{aligned}
& \frac{u_{r}}{u_{r}^{M}}=u_{r 0}+A_{a}\left[1-e^{\left(-B_{a}(|L| / R)\right)}\right] \\
& \frac{u_{r}}{u_{r}^{M}}=u_{r 0}+A_{b}\left\{1-\left[B_{b} /\left(B_{b}+(|L| / R)\right)\right]^{2}\right\}
\end{aligned}
$$

Eşitliklerdeki $\mathrm{u}_{\mathrm{r} 0}$ aynada meydana gelen deformasyon $\quad \mathrm{u}_{\mathrm{r} 0}=0,22 \vartheta+0.19 ; \quad \mathrm{A}_{\mathrm{a}}=-0,22 \vartheta-0,19$; $B_{a}=0,73 \vartheta+0,81 ; A_{b}=-0,22 \vartheta+0,81 ; B_{b}=0,39 \vartheta+0,65$ ile belirlenir.

Vlachopoulos ve Diederichs (2009) ise LDP'nin aynaya olan uzaklık ve kazı yarıçapının yanı sıra plastik zon yarıçapına $\left(R_{p}\right)$ bağlı bir fonksiyon olduğunu belirtmiş ve aynada, aynanın önünde ve arkasındaki deformasyonların hesaplanmasında kullanılmak üzere sırasıyla Eşitlik 6,7 ve 8 'i önermişlerdir.

$$
\begin{aligned}
& \frac{u_{r 0}}{u_{r}^{M}}=\frac{1}{3} e^{-0,15 R^{*}} \\
& \frac{u_{r}}{u_{r}^{M}}=\frac{u_{r 0}}{u_{r}^{M}} e^{L / R} \\
& \frac{u_{r}}{u_{r}^{M}}=1-\left(1-\frac{u_{r 0}}{u_{r}^{M}}\right) e^{-\left((3 L / R) / 2 R^{*}\right)}
\end{aligned}
$$

Eşitliklerdeki $\mathrm{u}_{\mathrm{r} 0}$ aynadaki deformasyon, $\mathrm{R}_{\mathrm{p}}$ plastik zon yarıçapı ve $R^{*}=R_{p} / R$ ile belirlenmektedir. Tünel çevresinde meydana gelecek en büyük deformasyon $\left(u_{r}^{M}\right)$ düzlem-birim deformasyon (plain-strain) analizi ile belirlenebilmektedir.

Basarir vd. (2010) radyal deformasyonu $\left(u_{r}\right)$ tünel yarıçapına $(\mathrm{R})$ göre normalize edip düzlem-birim deformasyon analizine gerek olmadan kaya kütlesi 
sınıflama sistemlerinden RMR, aynaya olan uzaklık ve yarıçap kullanılarak LDP'nin belirlenebileceğini vurgulamışlardır. Uzunlamasına yönde tünel aynası önünde $(L / R \leq 0)$ ve arkasında $(L / R \geq 0)$ oluşacak deformasyonların tahmin edilmesine yönelik sırasıyla Eşitlik 9 ve 10'u önermişlerdir.

$\frac{u_{r}}{R}=a R M R^{b} c^{L / D}$

$\frac{u_{r}}{R}=a R M R^{b} L / D^{c}$

Eşitliklerdeki RMR kaya kütle kalitesini verirken; a, b ve $c$ katsayıları derinliğe (100-400 m arasında, 100 m aralıklarla) bağlı olarak değişmektedir (Basarir vd., 2010).

Sakcali ve Yavuz (2019a)'un çalışmasında ise en büyük deformasyon ve aynada meydana gelen deformasyonun belirlenmesinde düzlem-birim deformasyon analizi yerine kaya kütlesi özellikleri ve arazi gerilmesinin kullanılabileceği sonucuna varılmıştır. 50-300 m arasında, $50 \mathrm{~m}$ aralıklarla değişen derinlikler için tünel çevresindeki en büyük deformasyon $\left(\mathrm{u}_{\mathrm{r}}^{\mathrm{M}}\right)$ ve aynadaki deformasyonunun $\left(u_{\mathrm{r} 0}\right)$ belirlenmesinde sırasıyla Eşitlik 11 ve $12^{\prime}$ in kullanılabileceği belirtilmiştir. Uzunlamasına yönde gelişen deformasyon dağılımının tahmin edilmesine yönelik ise Eşitlik 13'ü önermişlerdir.

$\frac{u_{r}^{M}}{R}=a\left(G S I . m_{i}\right)^{b}\left(\frac{\sigma_{c i}}{\sigma_{0}}\right)^{c}$

$\frac{u_{r 0}}{R}=a\left(G S I . m_{i}\right)^{b}\left(\frac{\sigma_{c i}}{\sigma_{0}}\right)^{c}$

$\frac{u_{r}-u_{r 0}}{u_{r}^{M}-u_{r 0}}=\frac{1,0628(L / R)}{0,571+(L / R)}$

Eşitliklerdeki GSI jeolojik dayanım indeksinin değeri, $\mathrm{m}_{\mathrm{i}}$ kaya malzemesi için Hoek-Brown sabiti, $\sigma_{\mathrm{ci}}$ kaya malzemesinin tek eksenli basınç dayanımı ve $\sigma_{0}$ arazi gerilmesidir. Eşitlik 11 ve $12^{\prime}$ de; a, b ve c katsayıları farklı derinlikler için değişmektedir (Sakcali ve Yavuz, 2019a).

LDP'nin oluşturulması için önerilen eşitliklerin yanı sıra bazı araştırmacılar sayısal modelleme yaparak tünel çevresindeki deformasyon dağılımlarını ve uzunlamasına yöndeki deformasyon profillerini belirlemişlerdir (Meguid vd., 2003; Hoek, 2004; Soroush vd., 2006; Bi ve Zhou, 2015; Sakcali ve Yavuz, 2019b).

LDP eşitlikleri hidrostatik koşullarda dairesel kesitli tünel çevresindeki deformasyon dağılımlarının belirlenmesi için önerilmiştir. Carranza-Torres ve Fairhurst (2000) çalışmasında dairesel olmayan tünellerde kesitin en büyük ve en küçük boyutunun ortalaması alınıp kazı yarıçapının belirlenebileceğini ve böylelikle kapanma-yakınsama yöntemiyle değerlendirmenin yapılabileceğini vurgulamıştır. Fakat farklı kazı kesitindeki tünellerde farklı boyut etkileri söz konusu olabilir. Bu nedenle deformasyon dağılımlarının belirlenmesinde 0 koşul için modelleme yapmak tünel aynası çevresindeki kaya kütlesinin davranışını daha iyi analiz edecektir.

Türkiye'de karayolu tünelleri genellikle modifiye at nalı kazı kesitinde açılmakta olup en çok tercih edilen 2 farklı boyuttaki kazı kesiti bu çalışma için ele alınmıştır. Zayıf kaya kütlesinde açılan 2 farkı boyuttaki modifiye at nalı kazı kesitli tüneller modellenmiştir. Kazı derinliği ve kaya kütlesi özellikleri en büyük deformasyonu etkilediği ve LDP oluşturulurken bu değere göre normalize edildiği için $250 \mathrm{~m}$ kazı derinliğinde GSI değeri 25, kaya malzemesi basınç dayanımı $\left(\sigma_{\mathrm{ci}}\right) 30 \mathrm{MPa}$ ve $\mathrm{m}_{\mathrm{i}}$ değeri 15 olan kaya kütlesindeki kazının modellenmesi yeterli görülmüştür.

Arazi gerilmesi oranları tünel aynası çevresindeki deformasyon dağılımlarını etkileyeceği için ise farklı k-oranı ele alınmıştır. 0,5 ile 2 arasında değişen $\mathrm{k}$ değerleri için yatay ve dikey gerilmeler verilerek kazı modelleri oluşturulmuştur. Modellerden tünel çevresinde meydana gelen deformasyon dağılımları ve yenilme zonunda meydana gelen değişimler incelenmiştir. Ayrıca, tünel tavanından tabanına doğru $15^{\circ}$ lik açısal değişimle belirlenen bölgelerden alınan deformasyon değerleri ile bu bölgeler için LDP'ler oluşturulmuştur. Dairesel olmayan tünellerde önerilen LDP eşitlikleri yerine özel koşullar için modelleme yapmanın daha uygun olacağı sonucuna varılmıştır. 


\section{Materyal ve Metot}

\subsection{Kaya kütlesi özelliklerinin belirlenmesi}

Kaya kütlesini tanımlamada Q (Barton vd., 1974), RMR (Bieniawski, 1989), RMi (Palmström, 1995), GSI (Hoek ve Brown, 1997) gibi farklı kaya kütlesi sınıflama sistemleri yaygın olarak kullanılmaktadır. Bu çalışmada kaya kütlesini karakterize etmek için GSI tercih edilmiş ve GSI sınıflama sisteminde zayıf kaya kütlesi için tanımlanan aralığa göre kaya kütlesi özellikleri belirlenmiştir.

GSI sınıflama sistemine göre zayıf kaya kütlesi için GSI değeri 10 ile 50 arasında değişmektedir (Hoek ve Brown, 1997). Benzer olarak RMR sınıflama sisteminde zayıf kaya kütlesinin tanımlandığı RMR aralığı 20-40'dır. Hoek ve Brown (1997)'a göre RMR değeri GSI değerinden 5 puan büyük olup RMR için tanımlanan zayıf kaya kütlesi aralığında GSI değeri 15 ile 35 arasında değişmektedir. Zayıf kaya kütlesini temsil etmesi için ortalama bir değer olarak GSI, 25 alınmıştır.

Kaya malzemesinin basınç dayanımı $\left(\sigma_{\text {ci }}\right)$ zayıf kaya kütlesi için 5 ile $25 \mathrm{MPa}$ arası, orta kalitede kaya kütlesi için 25 ile $50 \mathrm{MPa}$ arasında değişmektedir (Hoek ve Brown, 1997). Kaya kütlelerinde basınç dayanımı daha geniş aralıklarda değişebileceği göz önünde bulundurulup kaya malzemesinin basınç dayanımını $30 \mathrm{MPa}$ olarak belirlenmiştir.

Eşitlik 14 ile gösterilen Hoek-Brown yenilme kriterine göre kaya kütlesi yenilmesi $\mathrm{m}_{\mathrm{b}}, \mathrm{s}$, a HoekBrown sabitleri ve $\sigma_{\mathrm{ci}}$ ile tanımlanırken kaya malzemesinin yenilmesi $m_{i}$ ve $\sigma_{c i}{ }^{\prime}$ nin bir fonksiyonudur. $m_{i}$ değeri kaya kökeni, tipi, grubu ve dokusuna göre değişkenlik göstermekte olup ortalama bir değeri temsil etmesi için 15 alınmıştır. Modeller için zayıf kaya kütlesinin yenilme davranışını karakterize etmede kullanılan $\mathrm{m}_{\mathrm{b}}$, $\mathrm{s}$ ve a Hoek-Brown sabitleri Eşitlik 15, 16 ve 17 ile belirlenmiştir.

$$
\begin{aligned}
& \sigma_{1}^{\prime}=\sigma_{3}^{\prime}+\sigma_{c i}\left(m_{b} \frac{\sigma_{3}^{\prime}}{\sigma_{c i}}+s\right)^{a} \\
& m_{b}=m_{i} e^{\left(\frac{G S I-100}{28-14 D_{F}}\right)}
\end{aligned}
$$

$$
\begin{aligned}
& S=e^{\left(\frac{G S I-100}{9-3 D_{F}}\right)} \\
& a=\frac{1}{2}+\frac{1}{6}\left(e^{-G S I / 15}-e^{-20 / 3}\right)
\end{aligned}
$$

Eşitliklerdeki $\sigma_{1}^{\prime}$ en büyük asal gerilmeyi, $\sigma_{3}^{\prime}$ en küçük asal gerilmeyi, $\sigma_{\mathrm{ci}}$ kaya malzemesinin tek eksenli basınç dayanımını, $m_{i}$ kaya malzemesi için Hoek-Brown sabitini, $m_{b}$, $s$ ve a kaya kütlesi HoekBrown sabitlerini, GSI jeolojik dayanım indeks değerini vermektedir. $D_{F}$ ise örselenme faktörü olup 0 alınmıştır. Deformasyon modülünün $\left(E_{m}\right)$ belirlenmesinde Hoek ve Brown (1997)'da kullanılan Eşitlik 18 kullanılırken kayma $(G)$ ve hacimsel esneme modülünün $(\mathrm{K})$ belirlenmesinde sırasıyla Eşitlik 19 ve 20 kullanılmıştır (Itasca, 2005). Zayıf kaya kütlesini temsil etmesi için Poisson's oranı 0,3 olarak alınmıştır.

$$
\begin{aligned}
& E_{m}=\sqrt{\frac{\sigma_{c i}}{100}} 10^{((G S I-10) / 40)} \\
& G=\frac{E_{m}}{2(1+\vartheta)} \\
& K=\frac{(1+\vartheta) G}{(3 / 2)(1-2 \vartheta)}
\end{aligned}
$$

Modellerde kullanılacak zayıf kaya kütlesini temsil eden malzeme sabitleri $\mathrm{m}_{\mathrm{b}}=1,029 ; \mathrm{s}=0,00024$; $\mathrm{a}=0,531$ olarak hesaplanmış ve $\sigma_{\mathrm{ci}}=30 \mathrm{MPa}$ olarak seçilmiştir. Belirlenen kaya kütlesi özellikleri zayıf kayayı temsil etmesi için kullanılabilir (Sakcali ve Yavuz, 2019a). Kaya kütlesinin elastik özellikleri ise kayma ve hacimsel esneme modülü ile sırasıyla $\mathrm{G}=0,50 ; \mathrm{K}=1,08$ olarak tanımlanmıştır.

\subsection{Modifiye at nalı kesitli tünellerin boyutları}

Tüneller kullanım amaçlarına göre farklı boyut ve kesitlerde inşa edilmektedir. Kazı kesitleri dairesel olduğu gibi at nalı ve dikdörtgen kesitli de olabilmektedir. Madencilik amaçlı at nalı kesitli açılacak galerilerde farklı boyutlu kazılar gerçekleştirilebilse de B-5, B-8, B-10, B-14 ve B-18 en yaygın kullanılan at nalı kazı kesitleridir. $\mathrm{Bu}$ kesitlerde kazı genişliği 2,6 - 5,8 m, kazı yüksekliği ise 2,3 - 4,2 m arasında değişmektedir (Biron ve Arıoğlu, 1983; Yavuz, 2006). 
Geçmişten günümüze farklı at nalı kesitli tünellerde kazılar yapılsa da son yıllarda Türkiye'de karayolu tünellerinin birçoğu modifiye at nalı kazı kesitte gerçekleştirilmektedir. Türkiye' de karayolu tünelleri genellikle $10 \mathrm{~m}$ genişlik, $8 \mathrm{~m}$ yükseklikte ve $12 \mathrm{~m}$ genişlik, $9 \mathrm{~m}$ yükseklikte modifiye at nalı kesitte açılmaktadır (Kaya vd, 2011; KGM, 2013; Kanik, 2019).

Karayolu tünel projelerinde en çok tercih edilen bahsi geçen modifiye at nalı kesitteki tünel kazısı sonrası tünel çevresindeki kaya kütlesinde meydana gelecek deformasyon dağılımlarının belirlenmesi amacıyla zayıf kaya kütlesindeki kazı modellenmiştir.

\subsection{Modelleme çalışmaları}

Modelleme çalışması gerçekleştirilirken kaya kütlesi modellemelerinde yaygın olarak kullanılan, sonlu farklar yöntemine dayalı çözüm yapan FLAC3D kullanılmıştır (Itasca, 2005). Zayıf kaya kütlesi ve tünel geometrisinin yanı sıra model ağ sayısı, boyutları, başlangıç ve sınır koşulları modellemenin doğruluğu açısından büyük önem taşımaktadır. Bu parametrelerin etkilerin ortadan kaldırılması amacıyla farklı model ağları oluşturulmuş ve modelleme için en uygun koşullar belirlenmiştir.

Model sınırları ( $\mathrm{x}$ ve $\mathrm{z}$ yönünde) tünel üst yarıçapının 10 katı olarak belirlenirken kazı yönündeki (y yönü) model sınırı üst yarıçapın 20 katı olarak belirlenmiştir. Simetrik olacağı için dikey yönde yarı model oluşturulmuş ve iç sınırları yüzeye dik yönde harekete izin vermeyecek şekilde sınırlandırımıştır. Dış yüzeylerden ise dikey $\left(\sigma_{v}\right)$ ve yatay $\left(\sigma_{h}\right)$ yönde arazi gerilmeleri verilmiştir.

Kazının gerçekleştirildiği yerdeki dikey gerilme derinlik $(H)$ ve birim hacim ağırlığın $(\gamma)$ bir fonksiyonudur. Model sınırlarına uygulanacak dikey gerilme belirlenirken Eşitlik 21 kullanılmıştır (Brown ve Hoek, 1978).

$\sigma_{v}=\gamma \cdot H$
Dikey gerilme değişimini temsil eden zayıf kaya kütlesi ortalama birim hacim ağırlığı $23 \mathrm{kN} / \mathrm{m}^{3}$ olarak alınmıştır. $250 \mathrm{~m}$ derinlikteki bir kazı için dikey yöndeki dış sınıra $\left(\sigma_{\mathrm{v}}\right)$ 5,75 MPa'lık bir gerilme uygulanmıştır. Farklı arazi gerilmelerinde (yatay gerilme / dikey gerilme oranı) deformasyon değişimlerin incelenmesi amacıyla $\mathrm{k}$ değerinin 0,5 ile 2,0 arasında değiştiği durumlar için yatay gerilmeler belirlenmiştir. Model sınırlarındaki yatay gerilmeler $\left(\sigma_{\mathrm{h}}\right)$ ise k-oranı 0,$5 ; 0,75 ; 1 ; 1,5$ ve 2,0 için sırasıyla 2,$875 ; 4,3125 ; 5,75 ; 8,625$ ve $11,5 \mathrm{MPa}$ olarak uygulanmıştır.

Dikey ve yatay yönde dış yüzeylere uygulanan gerilmeler yine aynı yönlerdeki başlangıç gerilmesi (in situ stress) olarak uygulanmıştır. Kazısı yapılacak kaya kütlesi "model Hoek-Brown" ile tanımlanmış olup kazı, üst yarıçapın 10 katı kadar mesafede (y yönünde) "model null" kullanılarak modellenmiştir. Model boyutları ve sınır koşulları Şekil 1'de verilmiştir.
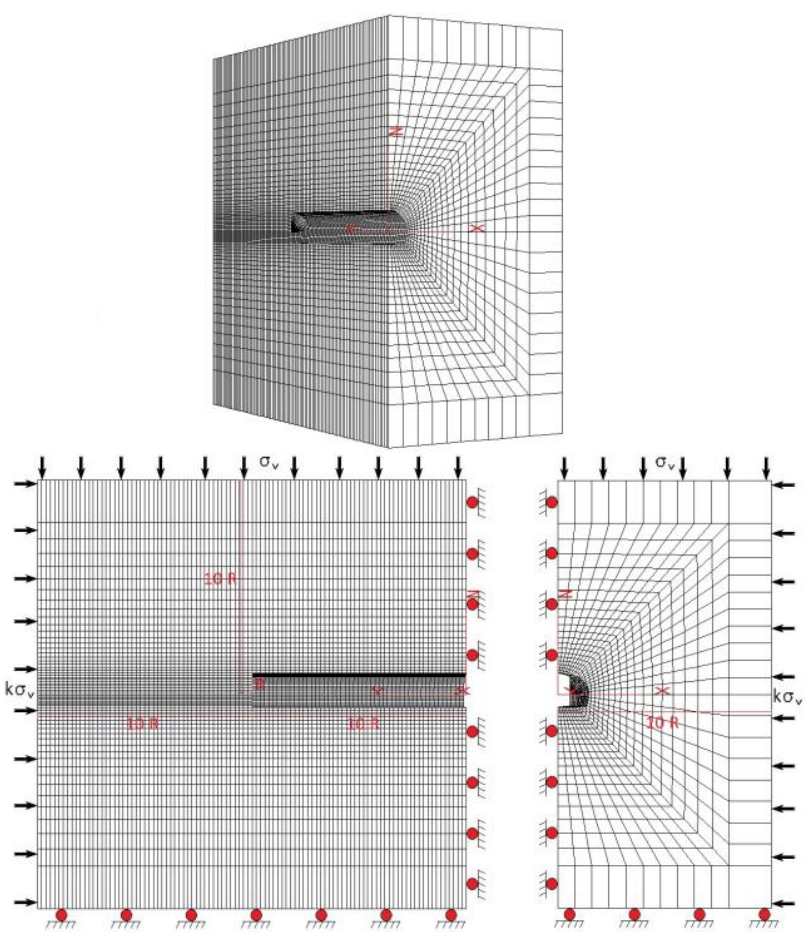

Şekil 1. Model boyutları ve sınır koşulları.

Kazı genişliği 10 m, kazı yüksekliği $8 \mathrm{~m}$ olan tünel modeli için zon sayısı 108000, grid noktası sayısı ise 113322'dir. Kazı genişliği 12 m, kazı yüksekliği 9 m olan tünel modelleri için ise zon ve grid noktası sayıları sırasıyla 129600 ve 135762 'dir. Çözümleme denge durumuna gelinceye kadar yaptırılmıştır. 


\section{Bulgular}

Dairesel kesitli tünellerde kazı sonrası tünel aynasına dik yöndeki mesafelerde tünel duvarında meydana gelecek deformasyon dağılımı LDP ile belirlenebilir. LDP eşitlikleri dairesel kesitli tüneller için kullanılırken dairesel olmayan kesitler için ise en büyük kesit ve en küçük kesit boyutunun ortalaması alınarak dairesel kesit gibi davrandığı varsayımı yapılarak belirlenebilir (Carranza-Torres, 2000).

Çizelge 1. Farklı boyutlardaki modifiye at nalı kesitli tünellerde değişen arazi gerilmeleri için tünel çevresindeki deformasyon dağılımları

k-oranı Kazı genişliği : 10 m, Kazı yüksekliği : 8 m

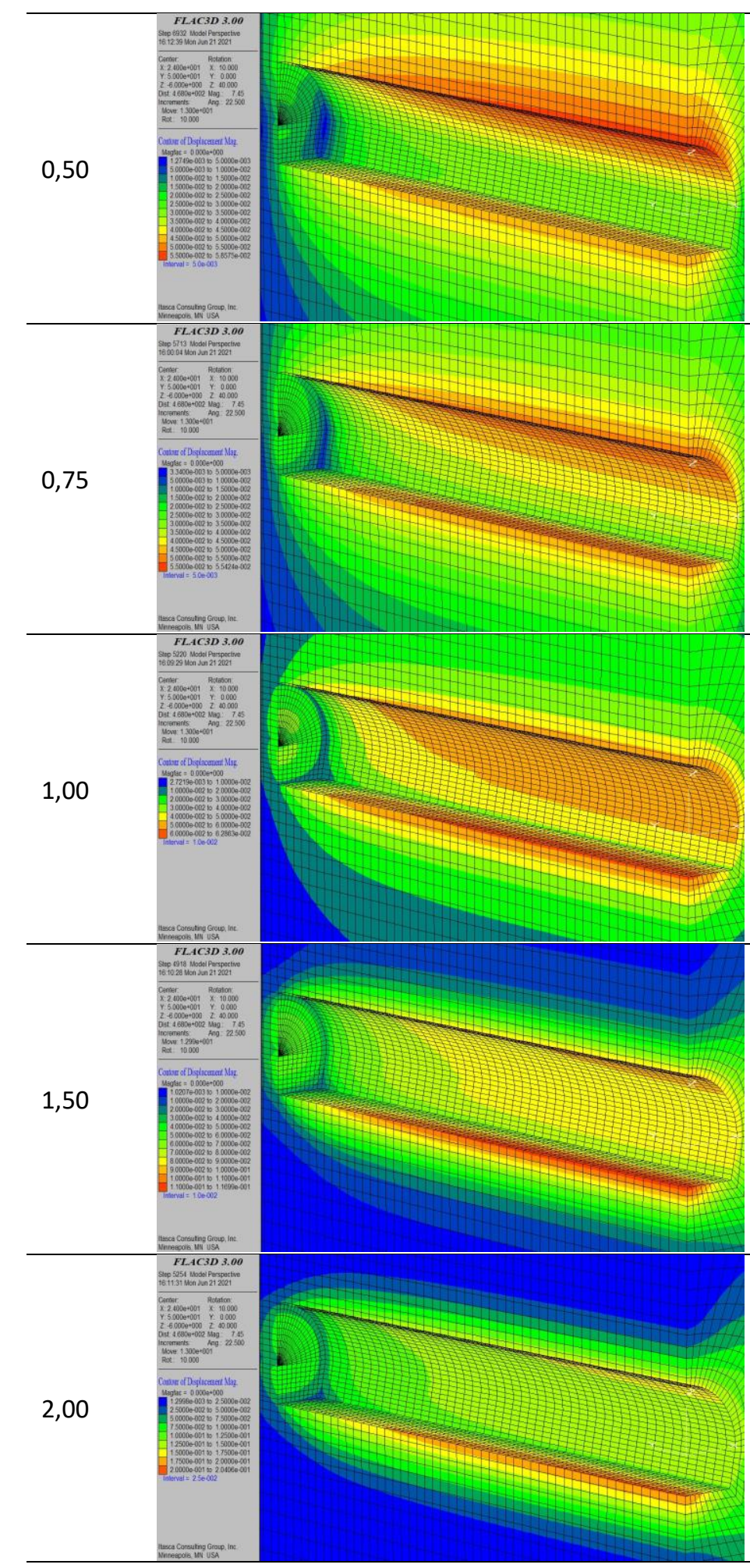

\section{Kazı genişliği : 12 m, Kazı yüksekliği : 9 m}

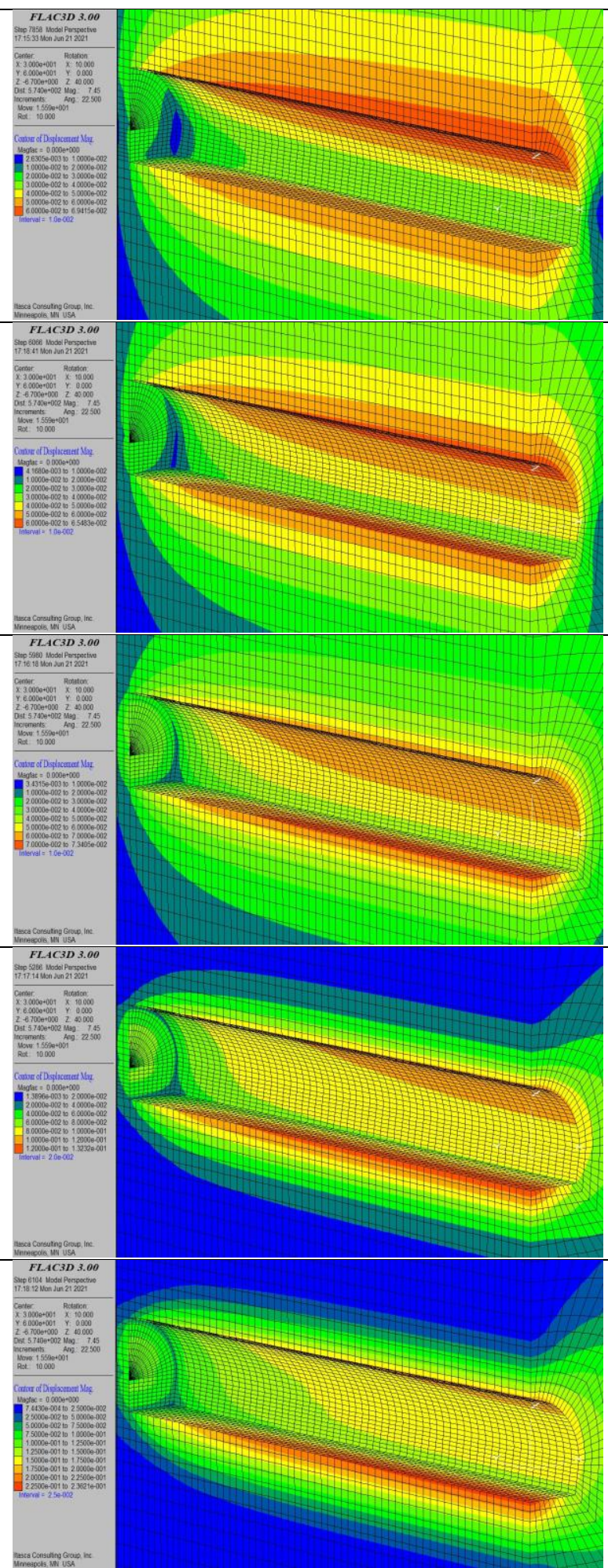


Fakat bu analitik yaklaşımda deformasyonlar belirlenirken varsayımdan yola çıkılmaktadır. Deformasyon dağılımını tünel koşulu için sayısal modelleme yaparak belirlemek daha gerçekçi sonuçlar verecektir. $10 \mathrm{~m}$ genişliğinde $8 \mathrm{~m}$ yüksekliğinde ve $12 \mathrm{~m}$ genişliğinde $9 \mathrm{~m}$ yüksekliğindeki zayıf kaya kütlesinde (GSI 25, $\sigma_{\mathrm{ci}} 30$ $\mathrm{MPa}, \mathrm{m}_{\mathrm{i}}$ 15) gerçekleştirilen modifiye at nalı kesitli tünel kazısı tahkimatsız olarak modellenmiştir. 250 $\mathrm{m}$ derinlikte farklı k-oranlarındaki gerilme koşulları için oluşturulmuş modellerde tünel çevresindeki deformasyon dağılımları Çizelge 1 'de verilmiştir.

Modifiye at nalı kesitli tünellerde deformasyon dağılımları kesit boyutuna göre değiştiği gibi arazi gerilme oranına bağlı olarak ta değişmektedir. Kesit yüksekliği ve kesit genişliğinin artması deformasyon değişimine neden olmaktadır. Yatay gerilme / dikey gerilme oranı değişiminin deformasyon dağılımına etkisine bakılacak olursa; $\mathrm{k}$ değeri $0,5^{\prime}$ den $0,75^{\prime} \mathrm{e}$ arttıkça maksimum deformasyonda azalma olurken 0,75'ten sonda maksimum deformasyonda artış söz konusu olmuştur. Yatay gerilme / dikey gerilme oranı 1'e kadar olan durumlar için maksimum deformasyon tünel tavanında meydana gelirken, 1 'de bu değer yaklaşık olarak eşit, 1'den büyük olduğu durumda ise tabanda olduğu görülmektedir.

Belirtilen zayıf kaya kütlesi koşullarında modifiye at nalı kesitte $10 \mathrm{~m}$ genişliğinde, $8 \mathrm{~m}$ yüksekliğinde açılan tünelde k-oranı değişimi ile meydana gelen yenilme zonu değişimi Şekil 2'de verilmiştir. Şekil $3^{\prime}$ te ise $12 \mathrm{~m}$ genişlik, $9 \mathrm{~m}$ yükseklikteki modifiye at nalı kesitli tünelde k-oranı değişiminde meydana gelen yenilme zonları gösterilmiştir. Şekil 2 ve 3 'te kırmızı renkli zonlarda kesme yenilmesi olmuş fakat şu an elastik özellik göstermektedir. Yeşil renkli zonlarda ise kesme yenilmesi söz konusudur. Şekil 2 ve 3'e bakıldığında, modifiye at nalı kesitli tünellerde yenilme zonu k-oranı değişimi ve kesit boyutlarına bağıı olarak değiştiği görülmektedir.

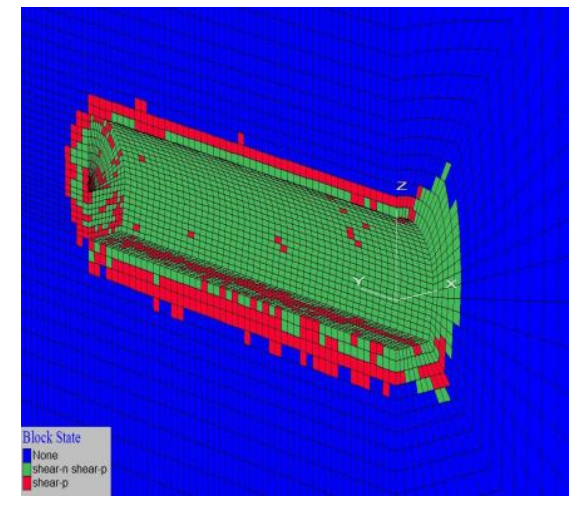

(a) $\mathrm{k}=0,5$

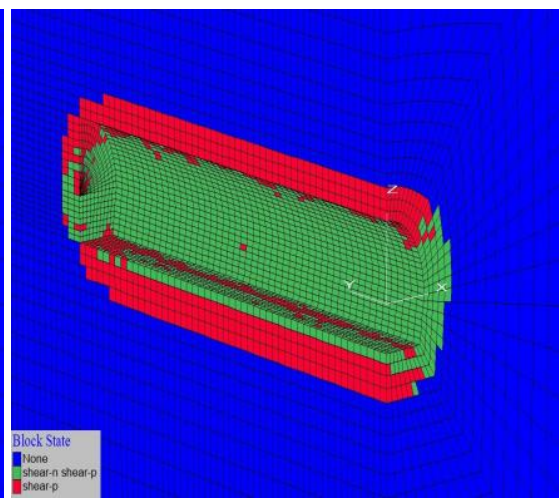

(b) $\mathrm{k}=0,75$

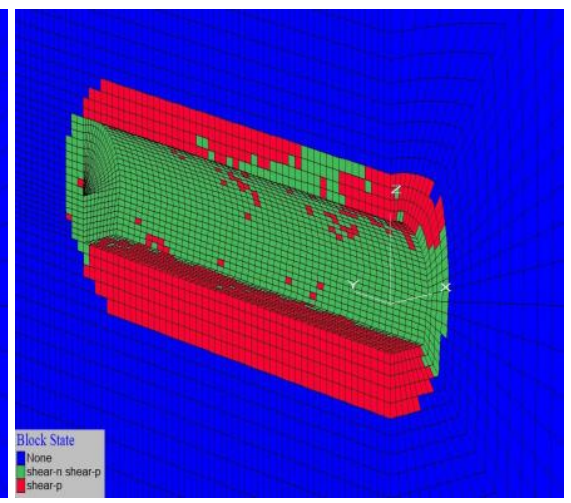

(c) $\mathrm{k}=1,00$

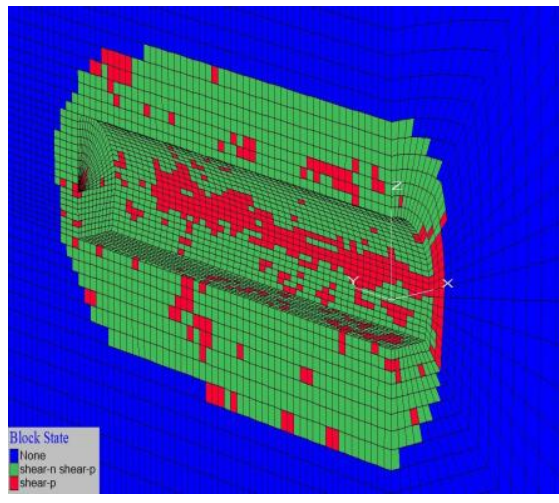

(d) $\mathrm{k}=1,50$

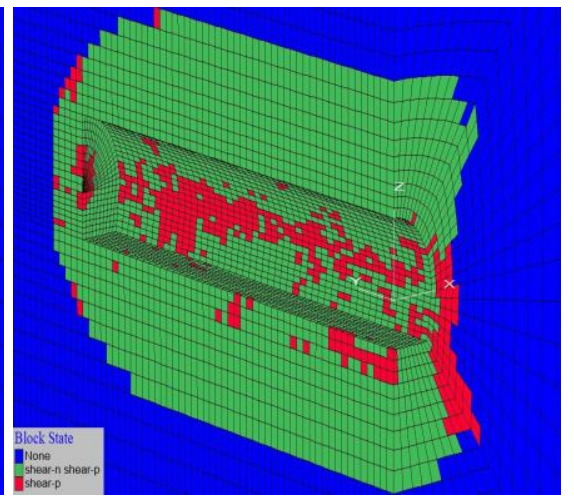

(c) $\mathrm{k}=2,00$

Şekil 2. Zayıf kaya kütlesinde $10 \mathrm{~m}$ genişliğinde, $8 \mathrm{~m}$ yüksekliğinde modifiye at nalı kesitli açılan tünellerde k-oranının yenilme zonlarındaki değişime etkileri; (a) $\mathrm{k}=0,50$ (b) $\mathrm{k}=0,75$ (c) $\mathrm{k}=1,00$ (d) $\mathrm{k}=1,50$ (e) $\mathrm{k}=2,00$. 


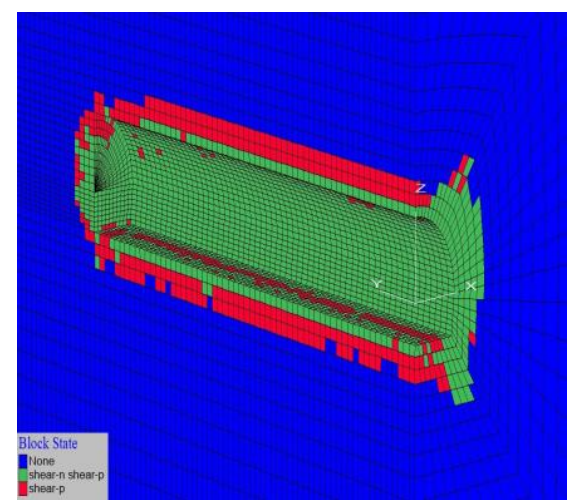

(a) $\mathrm{k}=0,5$

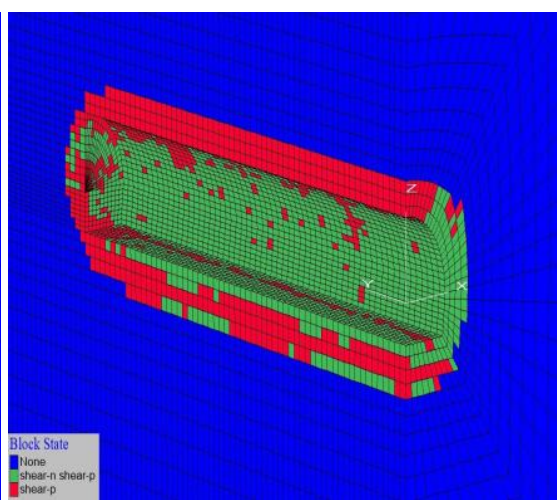

(b) $\mathrm{k}=0,75$

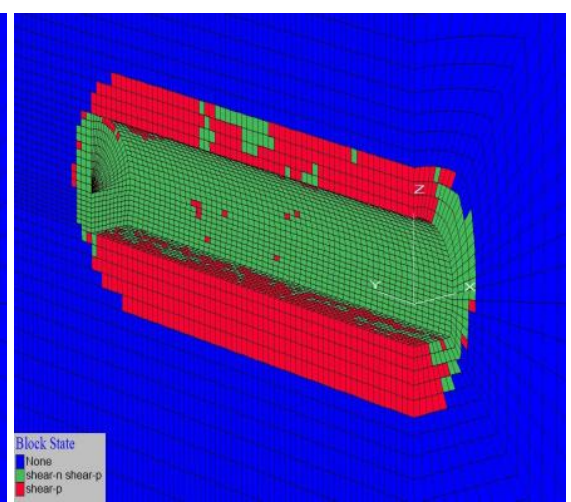

(c) $\mathrm{k}=1,00$

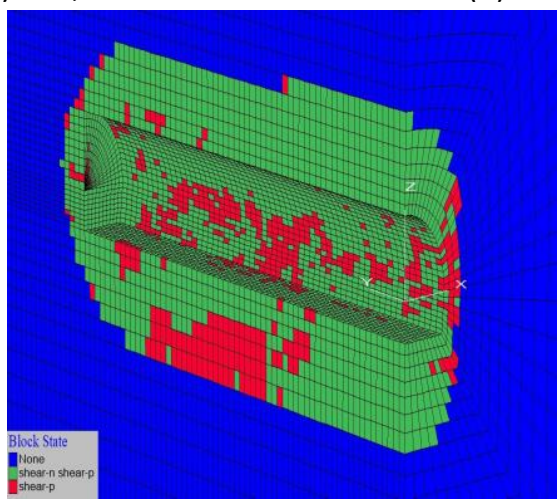

(d) $\mathrm{k}=1,50$

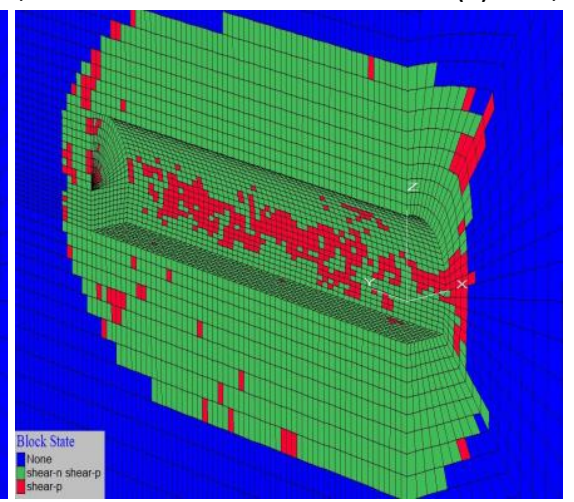

(c) $\mathrm{k}=2,00$

Şekil 3. Zayıf kaya kütlesinde $12 \mathrm{~m}$ genişliğinde, $9 \mathrm{~m}$ yüksekliğinde modifiye at nalı kesitli açılan tünellerde k-oranının yenilme zonlarındaki değişime etkileri; (a) $\mathrm{k}=0,50$ (b) $\mathrm{k}=0,75$ (c) $\mathrm{k}=1,00$ (d) $\mathrm{k}=1,50$ (e) $\mathrm{k}=2,00$.

Tavandan tabana doğru $15^{\circ}$ lik açısal değişimle belirlenen noktalardan alınan deformasyon değeri tavanda meydana gelen maksimum deformasyona göre normalize edilerek LDP’ler oluşturulmuştur.

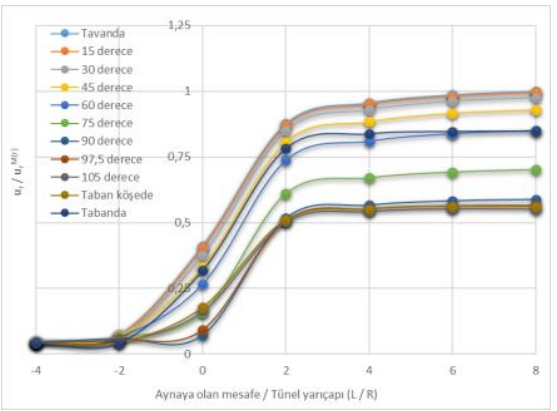

(a) $\mathrm{k}=0,5$

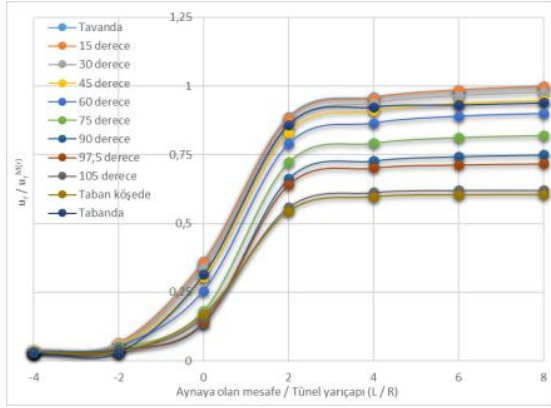

(b) $\mathrm{k}=0,75$

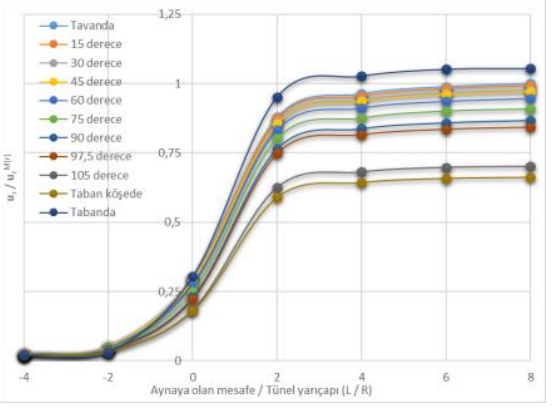

(c) $\mathrm{k}=1,00$

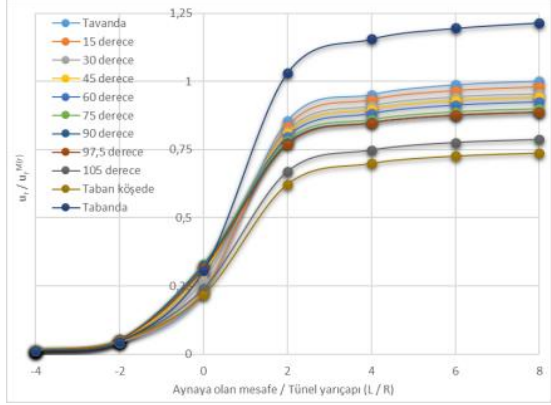

(d) $\mathrm{k}=1,50$

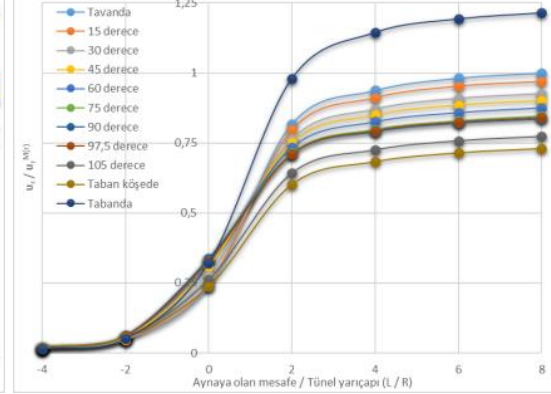

(c) $\mathrm{k}=2,00$

Şekil 4. Tünel kesitinin farklı noktalarında uzunlamasına deformasyon profili (LDP) değişimi (Genişlik: 10 m, yükseklik: 8 $\mathrm{m}) ;(\mathrm{a}) \mathrm{k}=0,50$ (b) $\mathrm{k}=0,75$ (c) $\mathrm{k}=1,00$ (d) $\mathrm{k}=1,50$ (e) $\mathrm{k}=2,00$. 


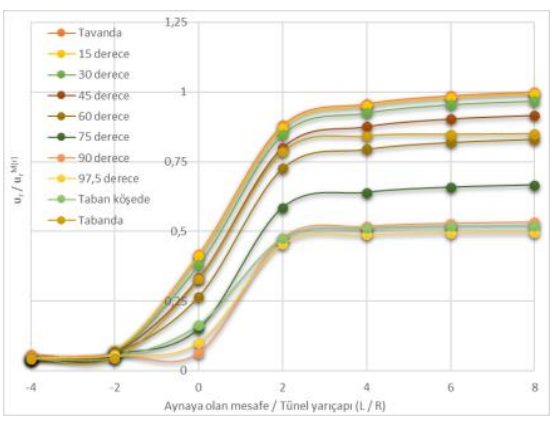

(a) $\mathrm{k}=0,5$

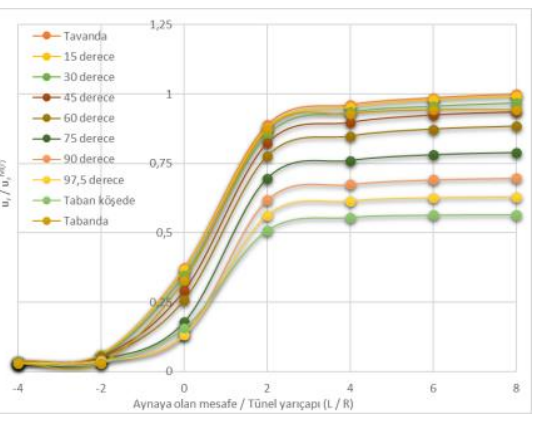

(b) $\mathrm{k}=0,75$

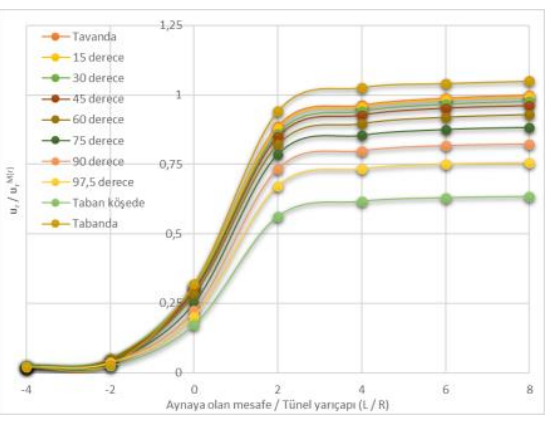

(c) $\mathrm{k}=1,00$

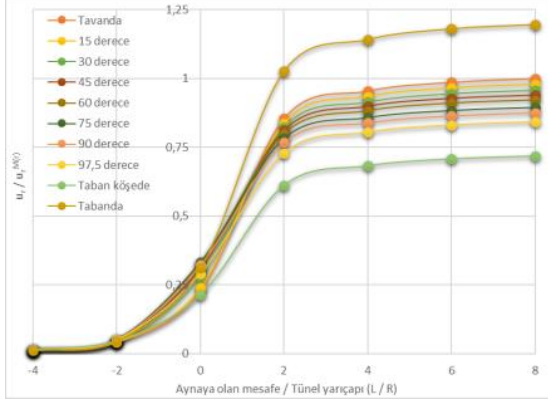

(d) $\mathrm{k}=1,50$

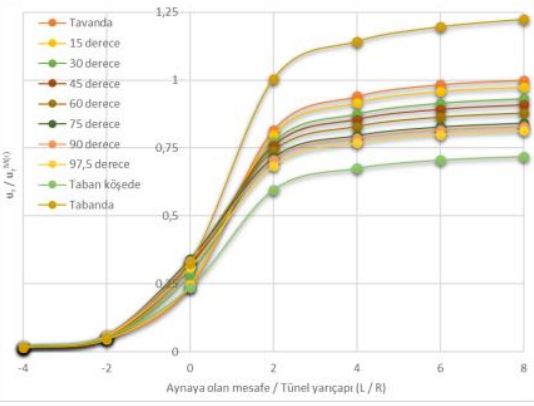

(c) $\mathrm{k}=2,00$

Şekil 5. Tünel kesitinin farklı noktalarında uzunlamasına deformasyon profili (LDP) değişimi (Genişlik: $12 \mathrm{~m}$, yükseklik: 9 m); (a) $\mathrm{k}=0,50$ (b) $\mathrm{k}=0,75$ (c) $\mathrm{k}=1,00$ (d) $\mathrm{k}=1,50$ (e) $\mathrm{k}=2,00$.

Genişliği $10 \mathrm{~m}$, yüksekliği $8 \mathrm{~m}$ ve genişliği $12 \mathrm{~m}$, yüksekliği $9 \mathrm{~m}$ olan farklı gerilmeler altında kazılan tünellerde kesitin farklı noktalardaki uzunlamasına deformasyon profilleri sırasıyla Şekil 4 ve 5 'te verilmiştir. Şekil 4 ve $5^{\prime}$ e bakıldığında modifiye at nalı kesitli tünellerde uzunlamasına deformasyon profili (LDP) tünel açılacak yerdeki arazi gerilmesi oranına bağıı olarak değiştiği gibi kesitteki farklı noktalarda da değiştiği görülmektedir. Ayrıca, kesit boyutlarının da deformasyon dağılımına etkisi söz konusu olduğu anlaşılmaktadır.

Farklı k-oranlarında $10 \mathrm{~m}$ genişlik, $8 \mathrm{~m}$ yükseklik ve $12 \mathrm{~m}$ genişlik, $9 \mathrm{~m}$ yükseklikte kazılan tünellerde tavan, yan duvar ve tabanda oluşan deformasyon dağılımları ise sırasıyla Şekil 6 ve 7'de verilmiştir. Arazi gerilmeleri tavanda normalize radyal deformasyonda büyük değişime neden olmamasına rağmen yan duvarda dağılım aralıkları açılmaktadır. Tünel tabanında ise tünel aynası arkasında yarıçap kadar aynaya olan mesafede büyük bir değişim söz konusu değil iken yarıçap kadar aynaya olan mesafe sonrasında k-oranı artışı ile dağılımda artmaktadır. Kesit boyutlarında çok büyük fark söz konusu olmadığı için, kesit boyutunun deformasyon dağılımlarına etkisi çok düşük olmuştur.

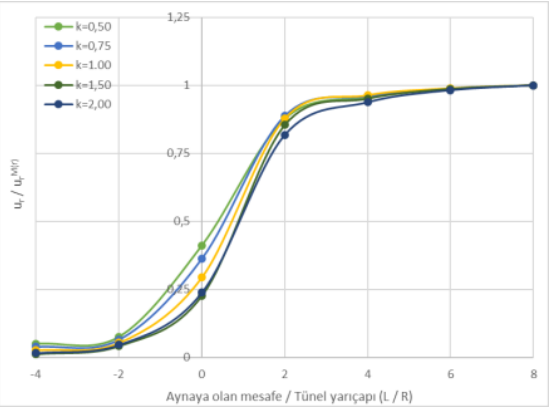

(a) Tavanda

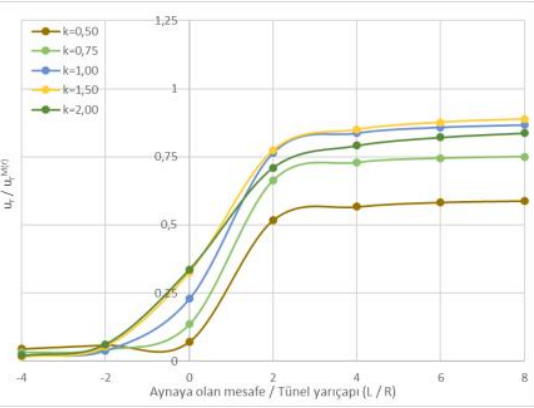

(b) Yan duvarda

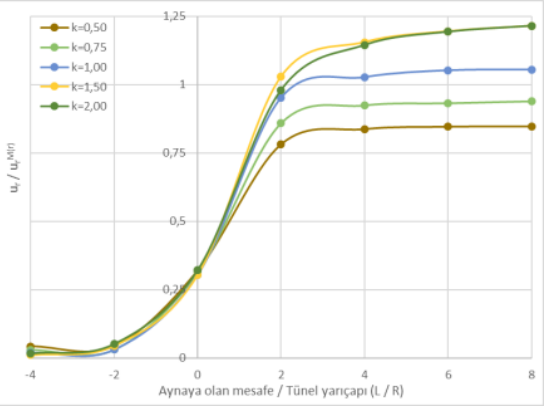

(c) Tabanda

Şekil 6. Farklı yatay gerilme / dikey gerilme oranlarında uzunlamasına deformasyon profilindeki (LDP) değişim (Genişlik: 10 m, yükseklik: 8 m); (a) Tavanda (b) Yan duvarda (c) Tabanda. 


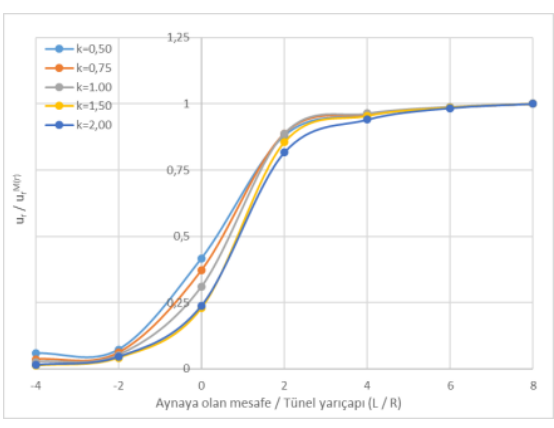

(a) Tavanda

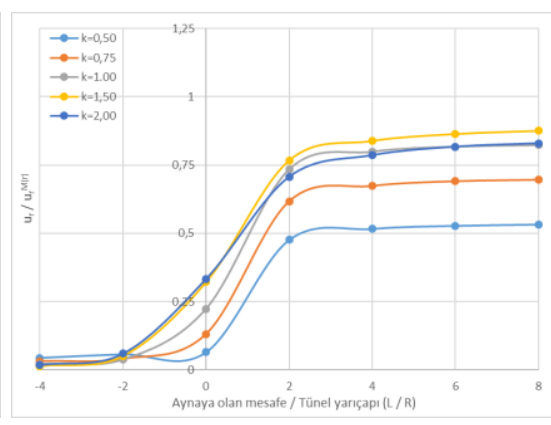

(b) Yan duvarda

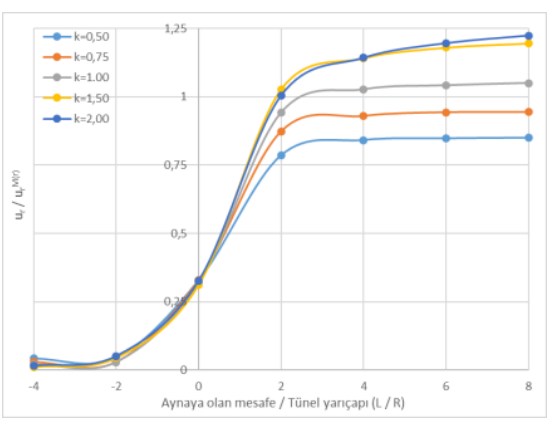

(c) Tabanda

Şekil 7. Farklı yatay gerilme / dikey gerilme oranlarında uzunlamasına deformasyon profilindeki (LDP) değişim (Genişlik: 12 m, yükseklik: 9 m); (a) Tavanda (b) Yan duvarda (c) Tabanda.

\section{Tartışma ve Sonuç}

Kapanma-yakınsama yöntemi tünel projelerinde deformasyon analizi ve tahkimat sistemi tercihinde kullanılan analitik bir yöntemdir. Bu yöntemde tünel aynasına göre uzunlamasına yönde deformasyon dağılımları LDP ile belirlenebilir. Uzunlamasına deformasyon profili hidrostatik koşulda açılan dairesel kesitli tüneller için kullanılabilir.

Modifiye at nalı kesitli açılan tünellerde deformasyon dağılımının belirlenmesi kazı öncesi tünel etrafındaki kaya kütlesinin davranışı hakkında bir ön bilgi sahibi olmamızı sağlayacaktır. Bu amaç doğrultusunda zayıf kaya kütlesini temsil eden bir kaya kütlesi tercih edilmiş ve Türkiye'de karayolu tünel projelerinde en çok tercih edilen 2 kazı profilinde gerçekleştirilen tünel kazısı tahkimatsız olarak modellenmiştir. Kazı derinliği ise ortalama bir değer olarak $250 \mathrm{~m}$ alınmıştır. Kaya kütlesi özellikleri ve derinlik değişimi ile tünel aynası çevresinde meydana gelecek deformasyonlar değişmesine rağmen LDP oluşturulurken maksimum deformasyona göre normalize edilerek bu parametrelerin etkileri yok edilmiştir. Bu nedenle, farklı zayıf kaya kütlesi özellikleri ve derinlikteki kazının modellenmesine gerek duyulmamıştır.

Deformasyon dağılımına, tünele etkiyen dikey arazi gerilmesi kadar yatay gerilmenin de etkisi söz konusudur. Modellere değişen k-oranları için farklı yatay gerilmeler uygulanmış ve bu parametrenin deformasyon dağılımı üzerine etkisine bakılmıştır. Bu çalışma ile elde edilen sonuçlar aşağıdaki gibi özetlenmiştir;
- Deformasyon dağılımına kesit boyutlarının etkisi söz konusudur.

- Yatay gerilme / dikey gerilme oranının (k-oranı) deformasyon dağııımına etkisi çok fazladır.

- Modifiye at nalı kesitli tünellerde kesitteki deformasyon dağııımına bakıldığında tavandan tabana doğru tünel çeperindeki kaya kütlesinde meydana gelen deformasyon azalmaktadır.

- Modifiye at nalı kesitli tünellerde k-oranı 1'den küçük olan arazi gerilmelerinde maksimum deformasyon tavanda oluşurken, 1'den büyük arazi gerilmelerinde tabandaki yükselmeden kaynaklı deformasyon en büyüktür. Hidrostatik koşulda ise tavan ve tabandaki deformasyon yaklaşık olarak eşit ve maksimumdur.

- Arazi gerilmesi oranının LDP değişimine etkisine bakıldığında tavanda çok büyük farklılıklar gözükmese de yan duvar ve tabanda k-oranı değişiminin LDP üzerinde etkili olduğu görülmektedir.

\section{Kaynaklar}

Barton, N., Lien, R. and Lunde, J., 1974. Engineering classification of rock masses for the design of tunnel support. Rock Mech., 6(4), 189-239.

Basarir, H., Genis, M. and Ozarslan, A., 2010. The analysis of radial displacements occurring near the face of a circular opening in weak rock mass. Int. J. Rock Mech. Min. Sci., 47(5), 771-783.

Bi, J. and Zhou, X.P., 2015. Numerical simulation of zonal disintegration of the surrounding rock masses around a deep circular tunnel under dynamic unloading. Int. J. Comp. Meth., 12(3), 1550020, 1-23. 
Bieniawski, Z.T., 1989. Engineering rock mass classifications. Wiley, New York, 251.

Biron, C. and Arioglu, E., 1983. Design of supports in mines. John Wiley \& Sons, New York, 283.

Brown, E.T. and Hoek, E., 1978. Trends in relationships between measured and in situ stresses and depth. Int. J. Rock Mech. Min. Sci \& Geomech. Abstr., 15(4), 211215.

Carranza-Torres, C. and Fairhurst, C., 2000. Application of the convergence-confinement method of tunnel design to rock masses that satisfy the Hoek-Brown failure criterion. Tunn. Undergr. Sp. Technol. 15, 187213.

Chern, J.C., Shiao, F.Y. and Yu, C.W., 1998. An empirical safety criterion for tunnel construction. Proceed of the Reg Symp on Sediment Rock Eng., 222-227.

Corbetta, F., Bernaud, D. and Nguyen-Minh., D., 1991. Contribution a la methode convergerce-confinement par le principe de la similitude. Rev. Fr. Geotech., 54, 5-11.

Hoek, E., 1999. Personal communication conducted by Carranza-Torres and Fairhurst. Taken from CarranzaTorres and Fairhurst (2000).

Hoek, E., 2004. Numerical modelling for shallow tunnels in weak rock - unpublished notes.

Hoek, E. and Brown, E.T., 1997. Practical estimates of rock mass strength. Int J Rock Mech Min Sci., 34(8), 11651186.

Itasca, 2005. Version 3.0 user manuals. Itasca Consulting Group, Inc. Mill Place, Minnesota.

Kanik, 2019. Evaluation of the limitations of $\mathrm{RMR}_{89}$ system for preliminary support selection in weak rock class. Comp. Geotech., 115, 103159, 1-11.

Kaya, A., Bulut, F., Alemdağ, S. and Sayin, S., 2011. Analysis of support requirements for a tunnel portal in weak rock: A case study from Turkey. Sci. Res. Ess., 6(31), 6566-6583.

KGM (Karayolları Genel Müdürlüğü), 2013. NATM uygulamalı yeraltı tünel işleri teknik şartnamesi. Karayolları Genel Müdürlüğü, Ankara.
Meguid, M.A., Rowe, R.K. and Lo, K.Y., 2003. Threedimensional analysis of unlined tunnels in rock subjected to high horizontal stresses. Can. Geotech. J., 40, 1208-1224.

Palmström, A., 1995. RMi-A rock mass characterization system for rock engineering purposes. PhD. Thesis Norway: University of Oslo, 400.

Panet, M. and Guenot, A., 1982. Analysis of convergence behind the face of a tunnel. Proceed Int Sym Tunneling, Inst Min Metall., 197-204.

Panet, M., 1995. Calcul des tunnels par la methode convergence-confinement. Press de l'ecole Natinale des Ponts et Chaussees.

Sakcali, A. and Yavuz, H., 2019a. Estimation of radial deformations around circular tunnels in weak rock masses through numerical modelling. Int. J. Rock. Mech. Min. Sci., 123, 104092, 1-14.

Sakcali, A. and Yavuz., H., 2019b. Numerical modelling analysis of radial deformations around a circular tunnel excavated in weak rock masses. Süleyman Demirel Uni J Nat Appl Sci., 23(1), 66-73.

Soroush, A., Foroozan, R. and Asadollahi, P., 2006. Simulation of 3D effect of excavation face advancement using a neural network trained by numerical models. E. J. Geotech. Eng., 11, 1-6.

Unlu, T. and Gercek, H., 2003. Effect of Poisson's ratio on the normalized radial displacements occurring around the face of a circular tunnel. Tunn. Undergr. Sp. Technol., 18(5), 547-553 (2003).

Vlachopoulos, N. and Diederichs, M.S., 2009. Improved displacement profiles for convergence confinement analysis of deep tunnels. Rock Mech. Rock Eng. , 42(2), 131-146.

Yavuz, H., 2006. Support pressure estimation for circular and non-circular openings based on a parametric numerical study. S. Afr. Inst. Min. Metal., 106, 129138. 